\title{
Amyloid Burden and Incident Depressive Symptoms in Cognitively Normal Older
}

\author{
Adults \\ Karra D Harrington1,2,3, Emma Gould1, Yen Ying Lim 2, David Ames3,4, Robert H. \\ Pietrzak $^{5,6}$, Alan Rembach ${ }^{2}$, Stephanie Rainey-Smith ${ }^{7,8}$, Ralph N. Martins ${ }^{7,8}$, Olivier \\ Salvado ${ }^{9}$, Victor L. Villemagne',10,11, Christopher C. Rowe ${ }^{10,11}$, Colin L. Masters ${ }^{2}$ and Paul \\ $=$ \\ Maruff',12 for the AIBL Research Group ${ }^{13}$ \\ 1. School of Psychology, Deakin University, Geelong, Victoria, Australia \\ 2. Florey Institute of Neuroscience and Mental Health, The University of Melbourne, Parkville, Victoria, Australia \\ 3. Academic Unit for Psychiatry of Old Age, Department of Psychiatry, The University of Melbourne, Parkville, Victoria, Australia \\ 4. National Ageing Research Institute, Parkville, Victoria, Australia \\ 5. United States Department of Veterans Affairs National Center for Posttraumatic Stress Disorder, Clinical Neurosciences Division, \\ VA Connecticut Healthcare System, West Haven, CT, USA \\ 6.Department of Psychiatry, Yale School of Medicine, New Haven, CT, USA \\ 7. Centre of Excellence for Alzheimer's Disease Research and Care, School of Exercise, Biomedical and Health Sciences, Edith Cowan \\ University, Perth, WA, Australia

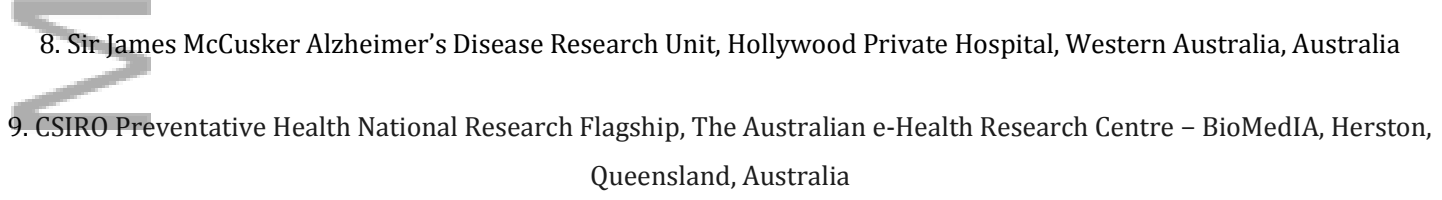 \\ 10. Department of Nuclear Medicine and Centre for PET, Austin Health, Heidelberg, VIC, Australia \\ 11. Department of Medicine, Austin Health, The University of Melbourne, Heidelberg, Victoria, Australia

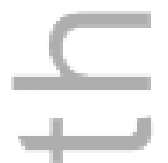 \\ 12. CogState Ltd., Melbourne, Victoria, Australia \\ 13. https://aibl.csiro.au

\section{Address for Correspondence:} \\ Karra Harrington \\ Florey Institute of Neuroscience and Mental Health \\ 155 Oak St, Parkville, VIC, 3052. \\ karra.harrington@florey.edu.au \\ Ph: 03-9388-1633 \\ Fax: 03-9387-5061
}

This is the author manuscript accepted for publication and has undergone full peer review but has not been through the copyediting, typesetting, pagination and proofreading process, which may lead to differences between this version and the Version of Record. Please cite this article as doi: $10.1002 /$ gps.4489

This article is protected by copyright. All rights reserved. 
AMYLOID BURDEN AND DEPRESSIVE SYMPTOMS

Keywords: amyloid, depression, Alzheimer's disease, cognitively normal Word Count of Body Text: 3508

\section{Abstract}

Objective: Several studies have reported that non-demented older adults with clinical depression show changes in amyloid- $\beta(\mathrm{A} \beta)$ levels in blood, cerebrospinal fluid, and on neuroimaging that are consistent with those observed in Alzheimer's disease (AD) patients. These findings suggest that $A \beta$ may be one of the mechanisms underlying the relation between the two conditions. We sought to determine the relation between elevated cerebral $\mathrm{A} \beta$, and the presence of depression across a 54 month prospective observation period.

Method: Cognitively normal older adults from the Australian Imaging Biomarkers and Lifestyle (AIBL) study of aging who were not depressed and had undergone a positron emission tomography (PET) scan to classify them as either high $\mathrm{A} \beta(\mathrm{n}=81)$ or low $\mathrm{A} \beta(\mathrm{n}=$ 278) participated. Depressive symptoms were assessed using the Geriatric Depression ScaleShort Form (GDS-S) at 18-month intervals over 54 months.

Results: Whilst there was no difference in probable depression between groups at baseline, incidence was 4.5 (95\% CI 1.3-16.4) times greater within the high A $\beta$ group (9\%) than the low $A \beta$ group (2\%) by the 54 month assessment.

Conclusions: Results of this study suggest that elevated A $\beta$ levels are associated with a 4.5fold increased likelihood of developing clinically significant depressive symptoms on follow 
AMYLOID BURDEN AND DEPRESSIVE SYMPTOMS

up in preclinical $\mathrm{AD}$. This underscores the importance of assessing, monitoring, and treating depressive symptoms in older adults with elevated $A \beta$.

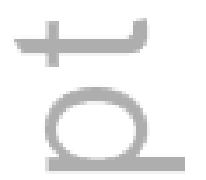

\section{Introduction}

Converging evidence indicates that life-time depression increases the risk of clinically classified Alzheimer's disease (AD; da Silva et al., 2013, Richard et al., 2013), and that increasing number, longer duration or higher frequency of depressive episodes across the lifespan may further increase this risk (Byers and Yaffe 2011; Piccinni, et al. 2013). In older adults depression and AD often co-occur and can be difficult to differentiate clinically (especially in mild $\mathrm{AD}$ ) due to overlap between the cognitive and functional impairments associated with the two diagnoses (Tsuno and Homma 2009; Wells 1979). There has been speculation that in older adults, depressive symptoms and AD may share a common biological mechanism and even that increased depressive symptoms are an early clinical indicator of the presence of AD-related pathophysiology (Byers and Yaffe 2011; Nascimento, et al. 2015).

Post mortem and in vivo studies suggest that amyloid-beta $(\mathrm{A} \beta)$ accumulation may provide a mechanistic link between depression and AD. For example, AD patients with clinical depression show greater numbers of neuritic $\mathrm{A} \beta$ plaques upon post mortem examination compared to those without depression (Meynen, et al. 2010; Rapp, et al. 2006). Further, non-demented older adults who met clinical criteria for major depressive disorder 
AMYLOID BURDEN AND DEPRESSIVE SYMPTOMS

(MDD), or showed elevated depressive symptoms, were more likely to also have AD-like A $\beta$ levels determined from in vivo assessments of $\mathrm{A} \beta$ using positron emission tomography (PET) amyloid neuroimaging (Chung, et al. 2015b; Kumar, et al. 2011; Lavretsky, et al. 2009; Wu, et al.2014), cerebrospinal fluid (CSF) sampling (Gudmundsson, et al. 2001; Pomara, et al. 2012; Tsuruga, et al. 2014) or blood markers (Baba, et al. 2012; Kita, et al. 2009; Namekawa, et al.2013). However relationships between increased amyloid and depressive symptoms have not been observed consistently (Butters, et al. 2008; Chung, et al. 2015a; Madsen, et al. 2012; Reis, et al. 2012; Wilson, et al. 2014). Furthermore, the majority of studies linking A $\beta$ and depression conducted to date have been limited by their use of cross-sectional designs, non-representative clinical samples and have failed to account for potential confounds from key risk factors for dementia presence and severity, such as the apolipoprotein $\mathrm{E}(A P O E) \varepsilon 4$ allele within their samples (Harrington, et al. 2015).

The preclinical phase of AD may provide a unique context for studying the development of depressive symptoms and their relationship to $A \beta$, independent of issues related to overt cognitive and functional symptoms, or any reactive responses to such symptoms or diagnoses that occur in more advanced stages of the disease (McKhann, et al. 2011). The preclinical AD phase is proposed to commence up to 20 years prior to the clinical classification of dementia (Jack, et al. 2010; Sperling, et al. 2011; Villemagne, et al.) providing a long window within which relationships between depression and $\mathrm{A} \beta$ can be determined. Thus, prospective studies of the incidence of depressive symptoms throughout the preclinical phase of $\mathrm{AD}$ should provide understanding of their relationship to AD-related pathophysiology and any role they may have as a possible early clinical indicator of AD. 


\section{AMYLOID BURDEN AND DEPRESSIVE SYMPTOMS}

The aim of this study was to examine prospectively relationships between $A \beta$ and depressive symptoms in cognitively normal older adults enrolled in the Australian Imaging Biomarker and Lifestyle (AIBL) study of aging. As AIBL is an experimental study, designed to identify the link between amyloid accumulation and clinical manifestations across all stages of AD, Individuals with uncontrolled vascular risk factors, medical illnesses or psychiatric disorders which can confound these relationships are excluded. All individuals also undergo MRI to exclude the potential for non-amyloid CNS injury or disease (e.g. microvascular disease) to influence clinical outcomes. Therefore the AIBL sample provides a basis for examining the relationship between amyloid and the incidence of depressive symptoms in otherwise healthy and cognitively normal older adults. It was hypothesised that high levels of $\mathrm{A} \beta$, as identified on positron emission tomography (PET) neuroimaging, would be associated with increased incidence of clinically significant depressive symptoms over 54 months

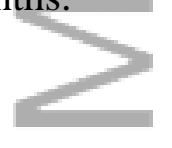

\section{ipants}

\section{Method}

\section{Participants}

The present study included 359 participants (168 male and 191 female) from the AIBL study who were classified as cognitively normal at the AIBL baseline assessment and had undergone a positron emission tomography (PET) scan to determine their cerebral A $\beta$ levels. Participants were not enrolled in the study if they had significant current depressive symptoms at the initial baseline assessment (i.e. Geriatric Depression Scale - Short Form score greater than 5/15 [Sheikh \& Yesavage, 1986]). 
AMYLOID BURDEN AND DEPRESSIVE SYMPTOMS

AIBL participants were recruited via a media campaign and referrals from specialised memory clinics during 2006-2008. Participants were excluded from enrolment in the AIBL study if they had a history of non-AD dementia, Parkinson's disease, schizophrenia, or bipolar disorder. Potential participants were also excluded at the commencement of the study if they had cancer (other than basal cell skin carcinoma) within the last two years, symptomatic stroke but not transient ischaemic attack, uncontrolled diabetes, or current regular alcohol use exceeding two standard drinks per day for women or four per day for men. These exclusion criteria ensured that individuals recruited to the study did not have frank pathology, other than $\mathrm{AD}$, that might cause cognitive impairment.

At each AIBL assessment (baseline, 18, 36, and 54 month follow-ups), a clinical review panel, consisting of geriatric psychiatrists, neurologists, geriatricians, and neuropsychologists, examined all available data to confirm the clinical status of participants and ensure appropriate group allocation. The panel reviewed all available clinical and cognitive information, including informant reports, functional and neuropsychological assessments, in order to reach consensus on each participant's clinical status (cognitively normal, mild cognitive impairment [MCI], or AD). Classification of MCI was based on internationally agreed criteria (Winblad, et al. 2004) and AD according to NINCDS-ADRDA criteria (McKhann, et al. 1984). All individuals included in the present study did not meet criteria for MCI or $\mathrm{AD}$ at the baseline assessment. Clinical classification was blinded to neuroimaging results. This process has been described in greater detail elsewhere (Ellis, et al. 2009). Independent of this process participants were also classified as either high $A \beta$ ( $n=$ 81) or low $A \beta(n=278)$ on the basis of $A \beta$ PET neuroimaging according to standardised 
AMYLOID BURDEN AND DEPRESSIVE SYMPTOMS

criteria (Jack, et al. 2008; Villemagne, et al. 2011). Retention of participants in the study was high across the 54 month study period, with 37 participants having withdrawn from the study by the 54 month assessment.

The AIBL study was approved by and complied with the regulations of three institutional research and ethics committees (St Vincent's Health, Austin Health, and Edith Cowan University). All participants provided written informed consent prior to participating in the study.

\section{Assessments}

Demographic and Clinical Characteristics. Demographic information was collected at the baseline assessment. Age, gender and medical history were self-reported. The Wechsler Test of Adult Reading (WTAR; Wechsler, 2001) was used to estimate the premorbid intelligence of participants. Functional ability was rated using the Clinical Dementia Rating scale (CDR; Morris, 1993). The Mini Mental State Examination (MMSE; Folstein et al., 1975) was used to screen global cognitive function. APOE genotype was determined using blood genotyping.

Depressive Symptoms. The Geriatric Depression Scale - Short Form (GDS-S; Sheikh \& Yesavage, 1986; Yesavage et al., 1982) was used to assess depressive symptoms. The GDS-S consists of 15 questions and uses a yes/no response format enabling ease of use for individuals with cognitive difficulties. The GDS-S is appropriate for use with older adults and is a reliable and valid measure of depressive symptoms in this population (Sheikh and Yesavage 1986; Strauss, et al. 2006; Yesavage et al. 1982). Clinically significant depressive symptoms, and probable clinical depression (hereafter referred to as depression), were 
AMYLOID BURDEN AND DEPRESSIVE SYMPTOMS

indicated by scores greater than 5 on the GDS-S. The cut score of 5 on the GDS-S has been reported to have sensitivity of $92.7 \%$ and specificity of $65.2 \%$ relative to cases identified using the International Classification of Diseases $10^{\text {th }}$ revision (ICD-10) criteria for major depression (Almeida and Almeida 1999).

Neuroimaging. PET neuroimaging in the AIBL study has been described in detail previously (Rowe, et al. 2010; Villemagne, et al. 2014). Briefly, 201 participants were administered Pittsburgh Compound B (PiB) and standardised uptake value (SUV) data were acquired 4070 minutes post-injection, 79 participants were administered ${ }^{18}$ F-florbetapir (FBP) and SUV data were acquired 50-70 minutes post-injection, and 80 participants were administered ${ }^{18} \mathrm{~F}$ flutemetamol (FLUTE) and SUV data were acquired 90-110 minutes post-injection. Data were summed and normalised to the cerebellar cortex SUV, giving the region-to-cerebellar ratio, termed SUV ratio (SUVR) for PiB (Rowe et al., 2010). The whole cerebellum was used as reference region for FBP, while the pons was used as reference region for FLUTE (Villemagne et al., 2014).

\section{Procedure}

Participants attended the research facility at each assessment time point after having fasted overnight. Once written consent to participate in the study was obtained, an $80 \mathrm{ml}$ blood sample was then taken; $0.5 \mathrm{ml}$ of which was forwarded for APOE genotyping at a clinical pathology laboratory. Next, trained research assistants conducted a clinical interview and comprehensive neuropsychological assessment including WTAR, MMSE, CDR, and 
AMYLOID BURDEN AND DEPRESSIVE SYMPTOMS

GDS-S. Neuroimaging was acquired on a separate day to the clinical data at each assessment time point.

\section{Data Analysis}

Neuroimaging results were coded as a dichotomous categorical variable using a PiB SUVR of 1.5, a FBP SUVR of 1.1, and a FLUTE SUVR of 0.62 as cut-offs for high/low A $\beta$ level in accordance with previous reports describing the definition of abnormal amyloid levels (Jack et al. 2008; Villemagne et al. 2011). For the GDS-S, performance was classified as a dichotomous categorical variable where a score greater than 5 was used to classify individuals as having depression (Sheikh and Yesavage 1986; Yesavage et al. 1982). Individuals were also classified as to whether or not they carried an $A P O E \varepsilon 4$ allele.

To test the hypothesis that high $\mathrm{A} \beta$ would be associated with increased incidence of depression over 54 months, first chi-square analysis was used to test for an association between $A \beta$ status and incidence of depression on the dichotomised GDS-S (score >5) at each assessment. Odds ratios with $95 \%$ confidence intervals (CI) were then calculated as a measure of effect for all significant associations. Next, a binary logistic regression analysis was conducted to evaluate the relationship between $\mathrm{A} \beta$ status at baseline and incident depression occurring at any assessment other than baseline over the 54 month study period. $A \beta$ status at baseline (low $A \beta$ vs. high $A \beta$ ), baseline variables that differed between the incident depression and no incident depression groups in bivariate analyses (i.e., age and $A P O E$ genotype), and an interaction term of $A \beta$ status x APOE genotype were entered 
AMYLOID BURDEN AND DEPRESSIVE SYMPTOMS

as independent variables, and incident depression status (incident depression vs. no incident depression) was entered as the dependent variable.

A post-hoc analysis was also conducted to examine to association between the incidence of depression and key clinical characteristics. Unique cases of incident depression occurring at any assessment were identified in the total sample according to categorisation based on the GDS-S score. Depressed and non-depressed participants were then compared on rates of self-reported history of a diagnosed depressive disorder, progression to meet clinical criteria for $\mathrm{MCI}$ or $\mathrm{AD}$ at the 54-month assessment, classification of high $\mathrm{A} \beta$, and withdrawal from the AIBL study using Chi-square analysis.

\section{Results}

Baseline demographic and clinical characteristics of the high and low A $\beta$ groups are summarised in Table 1 . The high A $\beta$ group was older and had a significantly greater proportion of $A P O E \& 4$ carriers than the low $\mathrm{A} \beta$ group. Figure 1 shows the median score and interquartile range on the GDS-S for the high and low A $\beta$ groups at each of the assessments. For all assessments, the upper value of the interquartile range was less than the standardised cut-off score (GDS-S >5) for classification of probable depression.

Figure 2 summarises the proportion of individuals who scored above 5 on the GDS-S for each of the $A \beta$ groups across each of the four assessments. Table 2 summarises the number of participants classified with depression in the total sample and within the high and low A $\beta$ groups across the four assessments. The number of new cases of depression presenting at 
AMYLOID BURDEN AND DEPRESSIVE SYMPTOMS

each of the four assessments within each group is also reported in Table 2. Chi-squared analysis was used to compare the proportion of participants classified as depressed between the $A \beta$ groups at each assessment. No association between $A \beta$ group and depression was identified at baseline, 18 or 36 months. However, there was a significant association between $\mathrm{A} \beta$ group and depression at the 54 month assessment, $\chi^{2}(1)=6.50, p<.05$. The odds-ratio for this relationship indicated that a classification of high $\mathrm{A} \beta$ made it 4.5 (95\% CI 1.3-16.4) times more likely to have depression at the 54 month assessment (Table 2). The logistic regression model predicting incident depression $(n=14,4.9 \%)$ over the 54-month study period indicated that the interaction of $\mathrm{A} \beta$ status $\mathrm{x} A P O E$ genotype predicted incident depression at a statistically significant level (Wald $\left.\chi^{2}(1)=6.75, p=0.009 ; \mathrm{OR}=5.73,95 \% \mathrm{CI}=1.53-21.38\right)$. In this model, age (Wald $\left.\chi^{2}(1)=0.75, \mathrm{p}=0.38\right), \mathrm{A} \beta$ status alone (Wald $\chi^{2}(1)=0.48, \mathrm{p}=0.49$ ) and APOE genotype alone (Wald $\chi^{2}(1)=1.23, \mathrm{p}=0.27$ ) were not significant predictors of incident depression.

There were 20 unique cases of depression identified in the total sample, of which 6 (4 low $A \beta, 2$ high $A \beta$ ) were classified as depressed at least twice in the 54 month study period. Table 3 summarises the clinical characteristics of both the depressed and non-depressed groups. Chi-square analysis (see Table 3) indicated that the depressed group was more likely to self-report a history of a diagnosed depressive disorder, $\chi^{2}(1)=4.49, p<.05$, and to progress to meet clinical criteria for MCI or $\mathrm{AD}$ at the 54-month assessment, $\chi^{2}(1)=15.39, \mathrm{p}$ $<.05$. From the depressed group, $30 \%$ of participants $(n=6)$ progressed to MCI or AD in the study period. Incidence of depression and progression to MCI or AD occurred at the same assessment for $10 \%(\mathrm{n}=2)$ of the depressed group. Depressed and non-depressed groups were 
AMYLOID BURDEN AND DEPRESSIVE SYMPTOMS

equally likely to be classified as high $\mathrm{A} \beta, \chi^{2}(1)=0.67, \mathrm{p}>.05$ and withdrew from the AIBL study at the same rate, $\chi^{2}(1)=0.01, p>.05$.

\section{Discussion}

The hypothesis that high $\mathrm{A} \beta$ would be associated with increased incidence of clinically significant depressive symptoms, and probable depressive disorder, was supported. Cognitively normal individuals with low levels of depressive symptoms were followed for 54 months. The incidence of clinically significant depressive symptoms occurring after enrolment remained low for the entire sample (1-9\%). However, relative to the low A $\beta$ group, the high $\mathrm{A} \beta$ group was 4.5 times more likely to exhibit clinically significant depressive symptoms by the 54 month assessment. Additionally, high $\mathrm{A} \beta$ and carriage of an APOE $\varepsilon 4$ was predictive of the incidence of depression over 54 months. These findings suggest that AD-related neuropathology in cognitively normal older adults is associated with an increased incidence of depressive symptoms of clinical severity, particularly for individuals at increased risk of AD due to genetic factors. Importantly, of those who progressed to MCI or $\mathrm{AD}$ the incidence of depression and progression to MCI or dementia did not occur at the same time point for most individuals (66\%). As such it is unlikely that the observed increase in depressive symptom levels was a reaction to any realisation of cognitive and functional deficits. Instead, the accumulation of cerebral A $\beta$ may be one biological mechanism that contributes to the pathophysiology of both depression and $\mathrm{AD}$ at least in some people (Byers and Yaffe 2011).

This article is protected by copyright. All rights reserved. 


\section{AMYLOID BURDEN AND DEPRESSIVE SYMPTOMS}

The synergistic relationship observed between high $\mathrm{A} \beta$ and $A P O E \varepsilon 4$ carriage with increased incidence of depression observed in the present study is consistent with reports from an earlier study (Metti, et al. 2013). Furthermore, previous studies have reported that $A P O E \& 4$ carriage is associated with increased risk of depression in late life (Sureshkumar, et al. 2012; Yen, et al. 2007), and that this relationship is maintained even when controlling for vascular disease factors, indicating that the association is unlikely the result of vascular pathology (Yen et al. 2007). The current sample was selected specifically so as not to have significant vascular risk factors and therefore the relationship between depressive symptoms and $\mathrm{A} \beta$ observed here is unlikely to have been mediated by any cerebral vascular disorder. Individuals with depression and high $\mathrm{A} \beta$, who also carry an $A P O E \& 4$ allele have also been reported to be at a greater risk (40\% v. $4 \%)$ of developing dementia than non-carriers (Qiu, et al. 2015). Taken together these data suggest that in cognitively normal older adults, the major risk factors for $\mathrm{AD}$, and in particular their combination, also increase substantially the risk of depression.

The clinical and demographic characteristics of the incident cases of depression occurring at any assessment within the total sample of the current study were also explored. Results of these analyses indicated that the incident depression group was more likely to selfreport a history of depressive episodes. Given that risk for recurrence of depression increases with multiple episodes (American Psychiatric Association 2013; Gonzales, et al. 1985; Kessing, et al. 2000), the finding that individuals with current depression were also more likely to report a history of depressive episodes suggests that the current classification of depression based on the GDS-S is valid. Importantly, rates of prior history of depressive 
AMYLOID BURDEN AND DEPRESSIVE SYMPTOMS

episodes did not differ significantly between the high and low A $\beta$ groups (see Table 1).

Consequently, the difference in incidence of depression between groups is unlikely to have been due to the effects of any prior history of depression. The incident depression group was also more likely to progress to MCI or AD over the course of the study. This finding accords with results of an earlier study which also observed that depressive symptoms accelerated cognitive decline and increased risk of progression to $\mathrm{AD}$ in MCI patients with high $\mathrm{A} \beta$ burden (Brendel, et al. 2015). Importantly though, depressed and non-depressed individuals were equally likely to be classified as having high levels of $A \beta$. This indicates that the increased rate of $\mathrm{AD}$ progression was not driven by increased rates of high levels of $\mathrm{A} \beta$ within the depressed group, but rather that the combined presence of high levels of $A \beta$ and depression may have enhanced the rate of disease progression. This suggests that there is an interaction between the two conditions that increases an individual's risk of progressing into the later stages of $\mathrm{AD}$.

From a clinical perspective, the identification and validation of a profile indicating preclinical $\mathrm{AD}$ would be useful in informing diagnosis, formulation, and prognosis of individuals with late life depressive disorders. The results of this study indicated that nondemented individuals with high $\mathrm{A} \beta$ appear to be at a higher risk of developing a late life depressive disorder, which subsequently results in an accelerated rate of disease progression. Thus we believe that it is important for clinicians to monitor closely patients at risk of dementia for increases in depressive symptoms, particularly in the context of an individual with prior depressive episodes. The emergence of such a depressive disorder late in life, in 
AMYLOID BURDEN AND DEPRESSIVE SYMPTOMS

addition to progressive cognitive decline, may herald the onset of the AD process, as well as indicating a potentially increased rate of $\mathrm{AD}$ progression.

The current study is limited in several ways. While, the data here provide insight into the relationship between $A \beta$ and depression, it is important to highlight that the AIBL sample is an experimental sample and hence is not be representative of the broader population. Further investigation in community-based samples of older adults is required to ensure the generalizability of the relationship between $A \beta$ and depression.

Another limitation of the current study is that it did not consider the interaction of the relationship between depressive symptoms and $\mathrm{A} \beta$ with the cognitive and functional symptoms of AD. Due to the low incidence of depression within the AIBL sample, the current study did not have sufficient statistical power to evaluate this interaction. It is well established that $\mathrm{A} \beta$-related cognitive decline occurs in the preclinical stage of $\mathrm{AD}$ and it would be important to consider how the trajectory of this decline is influenced by the presence of a depressive disorder.

Additionally, the present study only considered the total score on the GDS-S, which is known to be a relatively coarse screening measure, as an indicator of overall depressive symptom severity. There may be a particular depressive symptom profile related more specifically to cerebral $\mathrm{A} \beta$ burden, or to other $\mathrm{AD}$-related pathology such as neurodegeneration, which may show progressive changes over time. For example, Donovan, et al. (2015) reported that dysphoria and apathy-anhedonia depressive symptoms, but not anxiety-concentration symptoms, were associated with reduced hippocampal volume independent of $A \beta$ in cognitively normal older adults without clinical depression. Thus, the 
AMYLOID BURDEN AND DEPRESSIVE SYMPTOMS

possibility of specific subsets of depressive symptoms that relate more strongly to AD

pathology warrants further investigation. By considering these factors, a profile of symptoms associated with preclinical AD can begin to be developed in order to enhance clinical identification of the disease in its earliest stages.

Nevertheless, results of the present study begin to contribute to the establishment of this profile by indicating that non-demented older adults with high $\mathrm{A} \beta$ are at increased risk of a late life depressive disorder, which may be associated with increased risk of progression to $\mathrm{AD}$ dementia.
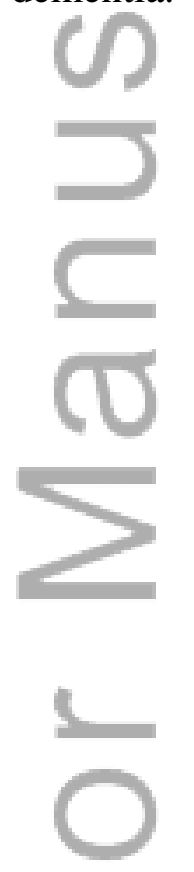

\section{Acknowledgments}

Alzheimer's Australia (Victoria and Western Australia) assisted with promotion of the study and the screening of telephone calls from volunteers. The AIBL team wishes to thank the clinicians who referred patients with AD to the study: Associate Professor Brian Chambers, Professor Edmond Chiu, Dr Roger Clarnette, Associate Professor David Darby, Dr Mary Davison, Dr John Drago, Dr Peter Drysdale, Dr Jacqueline Gilbert, Dr Kwang Lim, 
AMYLOID BURDEN AND DEPRESSIVE SYMPTOMS

Professor Nicola Lautenschlager, Dr Dina LoGiudice, Dr Peter McCardle, Dr Steve McFarlane, Dr Alastair Mander, Dr John Merory, Professor Daniel O’Connor, Dr Ron Scholes, Dr Mathew Samuel, Dr Darshan Trivedi, and Associate Professor Michael Woodward. We thank all those who participated in the study for their commitment and dedication to helping advance research into the early detection and causation of AD. -

1

\section{Financial Support}

Funding for the study was provided in part by the study partners [Australian Commonwealth Scientific Industrial and research Organization (CSIRO), Edith Cowan University (ECU), Mental Health Research Institute (MHRI), Alzheimer's Australia (AA), National Ageing Research Institute (NARI), Austin Health, CogState Ltd., Hollywood Private Hospital, Sir Charles Gardner Hospital]. The study also received support from the National Health and Medical Research Council (NHMRC) and the Dementia Collaborative Research Centres program (DCRC2), as well as ongoing funding from the Science and Industry Endowment Fund (SIEF). The authors also acknowledge the financial support of the Cooperative Research Centre (CRC) for Mental Health, from the Australian Government.

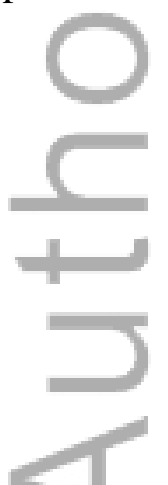

\section{Conflict of Interest}

KH and EG report no disclosures. C.L.M. is an advisor to Prana Biotechnology Ltd and a consultant to Eli Lilly. R.H.P. is a scientific consultant to Cogstate Ltd. P.M. is a full- 
AMYLOID BURDEN AND DEPRESSIVE SYMPTOMS

time employee of Cogstate Ltd. D.A. has served on scientific advisory boards for Novartis, Eli Lilly, Janssen, and Pfizer Inc. R.N.M. is a consultant to Alzhyme. C.C.R. has served on scientific advisory boards for Bayer Pharma, Elan Corporation, GE Healthcare and AstraZeneca; has received speaker honoraria from Bayer Pharma and GE Healthcare; and has received research support from Bayer Pharma, GE Healthcare, Piramal Lifesciences and Avid Radiopharmaceuticals. V.L.V. served as a consultant for Bayer Pharma; and received research support from a NEDO grant from Japan.

\section{Ethical Standards}

The authors assert that all procedures contributing to this work comply with the ethical standards of the relevant national and institutional committees on human experimentation and with the Helsinki Declaration of 1975, as revised in 2008. 
AMYLOID BURDEN AND DEPRESSIVE SYMPTOMS

\section{References}

Almeida OP \& Almeida SA 1999 Short versions of the geriatric depression scale: a study of their validity for the diagnosis of major depressive episode according to ICD-10 and DSM-

IV. International Journal of Geriatric Psychiatry 14 858-865.

American Psychiatric Association 2013 Diagnostic and statistical manual of mental disorders: DSM-5. Arlington, USA: American Psychiatric Association.

Baba H, Nakano Y, Maeshima H, Satomura E, Kita Y, Suzuki T \& Arai H 2012 Metabolism of amyloid- $\beta$ protein may be affected in depression. Journal of Clinical Psychiatry 73 115120.

Brendel M, Pogarell O, Xiong G, Delker A, Bartenstein P \& Rominger A 2015 Depressive symptoms accelerate cognitive decline in amyloid-positive MCI patients. European Journal of Nuclear Medicine and Molecular Imaging 42 716-724.

Butters MA, Klunk WE, Mathis CA, Price JC, Ziolko SK, Hoge JA, Tsopelas ND, Lopresti BJ, Reynolds CF, DeKosky ST, et al. 2008 Imaging Alzheimer Pathology in Late-Life Depression With PET and Pittsburgh Compound-B. Alzheimer disease and associated disorders 22 261-268.

Byers AL \& Yaffe K 2011 Depression and risk of developing dementia. Nature Reviews. Neurology 7 323-331.

Chung JK, Plitman E, Nakajima S, Chakravarty MM, Caravaggio F, Gerretsen P, Iwata Y \& Graff-Guerrero A 2015a Cortical Amyloid $\beta$ Deposition and Current Depressive Symptoms in Alzheimer Disease and Mild Cognitive Impairment. Journal of Geriatric Psychiatry and Neurology. 
AMYLOID BURDEN AND DEPRESSIVE SYMPTOMS

Chung JK, Plitman E, Nakajima S, Chow TW, Chakravarty MM, Caravaggio F, Gerretsen P, Brown EE, Iwata Y, Mulsant BH, et al. 2015b Lifetime History of Depression Predicts Increased Amyloid- $\beta$ Accumulation in Patients with Mild Cognitive Impairment. Journal of Alzheimer's Disease 45 907-919.

da Silva J, Gonçalves-Pereira M, Xavier M \& Mukaetova-Ladinska EB 2013 Affective disorders and risk of developing dementia: systematic review. The British Journal of Psychiatry 202 177-186.

Donovan N, Hsu D, Dagley A, Schultz A, Amariglio R, Mormino E, Okereke O, Rentz D, Johnson KA, Sperling RA, et al. 2015 Depressive Symptoms and Biomarkers of Alzheimer's Disease in Cognitively Normal Older Adults. Journal of Alzheimer's Disease Feb.

Ellis KA, Bush AI, Darby D, De Fazio D, Foster J, Hudson P, Lautenschlager NT, Lenzo N, Martins RN, Maruff P, et al. 2009 The Australian Imaging, Biomarkers and Lifestyle (AIBL) study of aging: methodology and baseline characteristics of 1112 individuals recruited for a longitudinal study of Alzheimer's disease. International Psychogeriatrics 21 672-687.

Folstein MF, Folstein SE \& McHugh PR 1975 “Mini-mental state”. Journal of Psychiatric Research 12 189-198.

Gonzales LR, Lewinsohn PM \& Clarke GN 1985 Longitudinal follow-up of unipolar depressives: An investigation of predictors of relapse. Journal of Consulting and Clinical Psychology 53 461-469.

Gudmundsson P, Skoog I, Waern M, Blennow K, Sigurdur P, Rosengren L \& Gustafson D 2001 The relationship betwen cerebrospinal fluid biomarkers and depression in elderly women. The American Journal of Geriatric Psychiatry 15. 
AMYLOID BURDEN AND DEPRESSIVE SYMPTOMS

Harrington KD, Gould E, Lim YY \& Maruff P 2015 Amyloid-beta and depression in healthy older adults: A systematic review. Australian and New Zealand Journal of Psychiatry 49. Jack CR, Knopman DS, Jagust WJ, Shaw LM, Aisen PS, Weiner MW, Petersen RC \& Trojanowski JQ 2010 Hypothetical model of dynamic biomarkers of the Alzheimer's pathological cascade. Lancet neurology 9 119-128.

Jack CR, Lowe VJ, Senjem ML, Weigand SD, Kemp BJ, Shiung MM, Knopman DS, Boeve BF, Klunk WE, Mathis CA, et al. 2008 (11)C PiB and Structural MRI Provide Complementary Information in Imaging of AD and Amnestic MCI. Brain : a journal of neurology $131665-680$.

Kessing LV, Andersen EW \& Andersen PK 2000 Predictors of recurrence in affective disorder — analyses accounting for individual heterogeneity. Journal of Affective Disorders 57 139-145.

Kita Y, Baba H, Maeshima H, Nakano Y, Suzuki T \& Arai H 2009 Serum amyloid protein in young and elderly depression: A pilot study. Psychogeriatrics 9 180-185.

Kumar A, Kepe V, Barrio JR, Siddarth P, Manoukian V, Elderkin-Thompson V \& Small GW 2011 Protein binding in patients with late-life depression. Archives Of General Psychiatry 68 1143-1150.

Lavretsky H, Siddarth P, Kepe V, Ercoli LM, Miller KJ, Burggren AC, Bookheimer SY, Huang S-C, Barrio JR \& Small GW 2009 Depression and anxiety symptoms are associated with cerebral FDDNP-PET binding in middle-aged and older nondemented adults. The American Journal of Geriatric Psychiatry 17 493-502.

This article is protected by copyright. All rights reserved. 
AMYLOID BURDEN AND DEPRESSIVE SYMPTOMS

Madsen K, Hasselbalch BJ, Frederiksen KS, Haahr ME, Gade A, Law I, Price JC, Knudsen GM, Kessing LV \& Hasselbalch SG 2012 Regular article: Lack of association between prior depressive episodes and cerebral [11C]PiB binding. Neurobiology of Aging 33 2334-2342. McKhann G, Drachman D, Folstein M, Katzman R, Price D \& Stadlan EM 1984 Clinical diagnosis of Alzheimer's disease: report of the NINCDS-ADRDA Work Group under the auspices of Department of Health and Human Services Task Force on Alzheimer's Disease. Neurology 34 939-944.

McKhann GM, Knopman DS, Chertkow H, Hyman BT, Jack CR, Kawas CH, Klunk WE, Koroshetz WJ, Manly JJ, Mayeux R, et al. 2011 The diagnosis of dementia due to Alzheimer's disease: Recommendations from the National Institute on Aging-Alzheimer's Association workgroups on diagnostic guidelines for Alzheimer's disease. Alzheimer's \& dementia: the journal of the Alzheimer's Association 7 263-269.

Metti AL, Cauley JA, Newman AB, Ayonayon HN, Barry LC, Kuller LM, Satterfield S, Simonsick EM \& Yaffe K 2013 Plasma Beta Amyloid Level and Depression in Older Adults. The Journals of Gerontology Series A: Biological Sciences and Medical Sciences 68 74-79. Meynen G, Van Stralen H, Smit JH, Kamphorst W, Swaab DF \& Hoogendijk WJG 2010 Relation between neuritic plaques and depressive state in Alzheimer's disease. Acta Neuropsychiatrica 22 14-20.

Morris JC 1993 The clinical dementia rating (CDR): Current version and scoring rules. Neurology 43 2412-2414.

Namekawa Y, Baba H, Maeshima H, Nakano Y, Satomura E, Takebayashi N, Nomoto H, Suzuki T \& Arai H 2013 Heterogeneity of elderly depression: Increased risk of Alzheimer's 
AMYLOID BURDEN AND DEPRESSIVE SYMPTOMS

disease and A $\beta$ protein metabolism. Progress in Neuro-Psychopharmacology and Biological Psychiatry 43 203-208.

Nascimento KKFd, Silva KP, Malloy-Diniz LF, Butters MA \& Diniz BS 2015 Plasma and cerebrospinal fluid amyloid- $\beta$ levels in late-life depression: A systematic review and metaanalysis. Journal of Psychiatric Research 69 35-41.

Piccinni A, Origlia N, Veltri A, Vizzaccaro C, Marazziti D, Vanelli F, Moroni I, Domenici L \& Dell'Osso L 2013 Neurodegeneration, $\beta$-amyloid and mood disorders: state of the art and future perspectives. International Journal of Geriatric Psychiatry 28 661-671.

Pomara N, Bruno D, Sarreal AS, Hernando RT, Nierenberg J, Petkova E, Sidtis JJ, Wisniewski TM, Mehta PD, Pratico D, et al. 2012 Lower CSF amyloid beta peptides and higher F2-isoprostanes in cognitively intact elderly individuals with major depressive disorder. The American Journal Of Psychiatry 169 523-530.

Qiu WQ, Zhu H, Dean M, Liu Z, Vu L, Fan G, Li H, Mwamburi DM, Steffens DC \& Au R 2015 Amyloid-associated depression and ApoE4 allele: longitudinal follow-up for the development of Alzheimer's disease. International Journal of Geriatric Psychiatry Aug 6 [Epub ahead of print].

Rapp MA, Schnaider-Beeri M, Grossman HT, Sano M, Perl DP, Purohit DP, Gorman JM \& Haroutunian V 2006 Increased hippocampal plaques and tangles in patients with Alzheimer disease with a lifetime history of major depression. Archives Of General Psychiatry 63 161167.

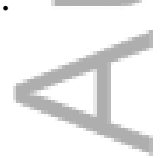

This article is protected by copyright. All rights reserved. 
AMYLOID BURDEN AND DEPRESSIVE SYMPTOMS

Reis T, Brandão CO, Freire Coutinho ES, Engelhardt E \& Laks J 2012 Cerebrospinal Fluid Biomarkers in Alzheimer's Disease and Geriatric Depression: Preliminary Findings from Brazil. CNS Neuroscience \& Therapeutics 18 524-529.

Richard E, Reitz C, Honig LH, Schupf N, Tang MX, Manly JJ, Mayeux R, Devanand D \& Luchsinger JA 2013 Late-life depression, mild cognitive impairment, and dementia. JAMA Neurology 70 383-389.

Rowe CC, Ellis KA, Rimajova M, Bourgeat P, Pike KE, Jones G, Fripp J, Tochon-Danguy H, Morandeau L, O'Keefe G, et al. 2010 Amyloid imaging results from the Australian Imaging, Biomarkers and Lifestyle (AIBL) study of aging. Neurobiology of Aging 31 1275-1283.

Sheikh JI \& Yesavage JA 1986 Geriatric Depression Scale: recent evidence and development of a shorter version. In Clinical gerontology: A guide to assessment and intervention. Ed TL Brink. New York: The Haworth Press.

Sperling RA, Aisen PS, Beckett LA, Bennett DA, Craft S, Fagan AM, Iwatsubo T, Jack CRJ, Kaye J, Montine TJ, et al. 2011 Toward defining the preclinical stages of Alzheimer's disease: Recommendations from the National Institute on Aging and the Alzheimer's Association workgroup. Alzheimer's and Dementia $\mathbf{1 .}$

Strauss E, Sherman \& Spreen O 2006 A compendium of neuropsychological tests:

Administration, norms, and commentary. New York: Oxford University Press.

Sureshkumar R, Bharath S, Jain S, Prakash O, Purushottam M, Thennarasu K, Mukherjee O, Sivakumar PT \& Varghese M 2012 ApoE4 and late onset depression in Indian population. Journal of Affective Disorders 136 244-248.

This article is protected by copyright. All rights reserved. 
AMYLOID BURDEN AND DEPRESSIVE SYMPTOMS

Tsuno N \& Homma A 2009 What is the association between depression and Alzheimer's disease? Expert Review Of Neurotherapeutics 9 1667-1676.

Tsuruga K, Sugawara N, Yasui-Furukori N, Takahashi I, Tsuchimine S, Kaneda A, Nakaji S \& Nakamura K 2014 A positive correlation between serum amyloid $\beta$ levels and depressive symptoms among community-dwelling elderly individuals in Japan. Neuropsychiatric Disease and Treatment 10 1621-1627.

Villemagne VL, Burnham S, Bourgeat P, Brown B, Ellis KA, Salvado O, Szoeke C, Macaulay SL, Martins R, Maruff P, et al. Amyloid $\beta$ deposition, neurodegeneration, and cognitive decline in sporadic Alzheimer's disease: a prospective cohort study. The Lancet Neurology 12 357-367.

Villemagne VL, Dore V, Yates P, Brown B, Mulligan RS, Bourgeat P, Veljanoski R, RaineySmith SR, Ong K, Rembach A, et al. 2014 En Attendant Centiloid. Advances in Research 2 $723-729$

Villemagne VL, Pike KE, Chételat G, Ellis KA, Mulligan RS, Bourgeat P, Ackermann U, Jones G, Szoeke C, Salvado O, et al. 2011 Longitudinal assessment of A $\beta$ and cognition in aging and Alzheimer disease. Annals of Neurology 69 181-192.

Wechsler D 2001 Wechsler test of adult reading: Examiner's manual. San Antonio, TX:

Psychological Corporation.

Wells CE 1979 Pseudodementia. American Journal of Psychiatry 136 895-900. Wilson RS, Capuano AW, Boyle PA, Hoganson GM, Hizel LP, Shah RC, Nag S, Schneider JA, Arnold SE \& Bennett DA 2014 Clinical-pathologic study of depressive symptoms and cognitive decline in old age. Neurology 83 702-709. 
AMYLOID BURDEN AND DEPRESSIVE SYMPTOMS

Winblad BA, Palmer KA, Kivipelto MA, Jelic VA, Fratiglioni LA, Wahlund LOA, Nordberg AA, Bäckman LA, Albert MA, Almkvist OA, et al. 2004 Mild cognitive impairment--beyond controversies, towards a consensus: report of the International Working Group on Mild Cognitive Impairment. Journal of internal medicine 240.

Wu KY, Hsiao IT, Chen CS, Chen CH, Hsieh CJ, Wai YY, Chang CJ, Tseng HJ, Yen TC, Liu CY, et al. 2014 Increased brain amyloid deposition in patients with a lifetime history of major depression: Evidenced on 18F-florbetapir (AV-45/Amyvid) positron emission tomography. European Journal of Nuclear Medicine and Molecular Imaging 41 714-722.

Yen YC, Rebok GW, Gallo JJ, Yang MJ, Lung FW \& Shih CH 2007 ApoE4 allele is associated with late-life depression: a population-based study. American Journal of Geriatric Psychiatry 15 858-868.

Yesavage JA, Brink TL, Rose TL, Lum O, Huang V, Adey MB \& Leirer VO 1982

Development and validation of a geriatric depression screening scale: A preliminary report. Journal of Psychiatric Research 17 37-49.

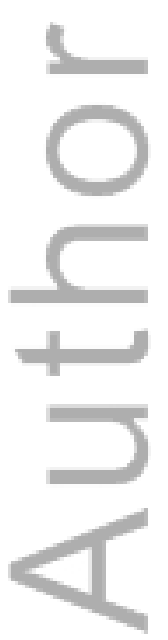

This article is protected by copyright. All rights reserved. 


\section{AMYLOID BURDEN AND DEPRESSIVE SYMPTOMS}

Table 1.

Mean (SD) of baseline demographic and clinical characteristics for the Low A $\beta$ and High A $\beta$ groups.

\begin{tabular}{llll}
\hline & Low A $\beta(\mathrm{n}=278)$ & High A $\beta(\mathrm{n}=81)$ & $p$ \\
\hline Age & $68.70(6.08)$ & $73.47(7.33)$ & .00 \\
Gender & $53 \%$ Female & $53 \%$ Female & .98 \\
Premorbid IQ (WTAR) & $108.26(7.01)$ & $109.65(6.84)$ & .12 \\
APOE4 carriers & $23 \%$ & $60 \%$ & .00 \\
MMSE- & $28.96(1.17)$ & $28.75(1.19)$ & .16 \\
CDR Total* & $0(0.5)$ & $0(0.5)$ & .16 \\
CDR-SOB* & $0(1.5)$ & $0(0.5)$ & .99 \\
Self-reported history of depression & $19 \%$ & $14 \%$ & .11 \\
GDS* & $0.00(8.00)$ & $0.00(2.00)$ & \\
\hline
\end{tabular}

\section{*Median (range) reported}

$\mathrm{WTAR}=$ Wechsler Test of Adult Reading, APOE4 $=$ Apolipoprotein $\varepsilon 4, \mathrm{CVRF}=$ Cardiovascular Risk Factor, MMSE $=$ Mini Mental State Examination, CDR = Clinical Dementia Rating, CDR-SOB = Clinical Dementia rating Sum of Boxes score, GDS - Geriatric Depression Scale 
AMYLOID BURDEN AND DEPRESSIVE SYMPTOMS

Table 2.

Number (\%) of cases of clinically significant depressive symptoms at each assessment time point for the Low AB and High A groups.

\begin{tabular}{|c|c|c|c|c|c|c|c|}
\hline & \multicolumn{2}{|c|}{ Total Sample } & \multicolumn{2}{|c|}{ Low $A \beta$} & \multicolumn{2}{|c|}{ High $A \beta$} & \multirow[b]{2}{*}{$\mathrm{p}$} \\
\hline & Total & New & Total & New & Total & New & \\
\hline Baseline & $5(1.4 \%)$ & - & $5(1.8 \%)$ & - & $0(0 \%)$ & - & .23 \\
\hline 18 months & $7(2.1 \%)$ & 7 & $4(1.5 \%)$ & 4 & $3(4.3 \%)$ & 3 & .15 \\
\hline 36 months & $7(2.1 \%)$ & 3 & $5(1.9 \%)$ & 3 & $2(3.1 \%)$ & 0 & .55 \\
\hline 54 months & $10(3.2 \%)$ & 5 & $5(1.9 \%)$ & 2 & $5(8.3 \%)$ & 3 & .01 \\
\hline
\end{tabular}

This article is protected by copyright. All rights reserved. 
AMYLOID BURDEN AND DEPRESSIVE SYMPTOMS

Table 3.

Characteristics of incident cases of clinically significant depressive symptoms (GDS-S >5)

\begin{tabular}{lcc}
\hline & Depressed & Non-depressed \\
\hline Unique cases & 20 & 339 \\
Self-reported history of depressive disorder & $7(35 \%)$ & $55(16 \%)^{*}$ \\
MCI/AD Progression & $6(30 \%)$ & $21(6 \%)^{*}$ \\
AIBL Withdrawal & $2(10 \%)$ & $35(10 \%)$ \\
High A $\beta$ Classification & $6(30 \%)$ & $75(22 \%)$ \\
\hline
\end{tabular}

$* p<0.05$

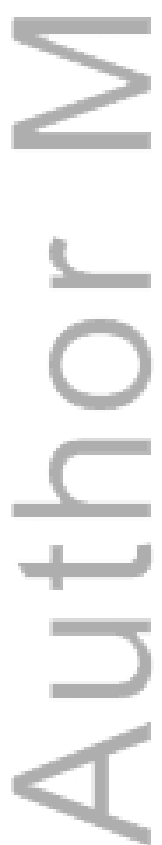

This article is protected by copyright. All rights reserved. 
AMYLOID BURDEN AND DEPRESSIVE SYMPTOMS

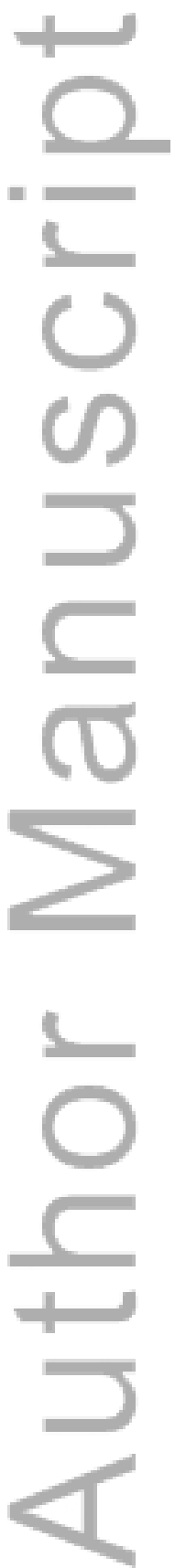

This article is protected by copyright. All rights reserved. 
AMYLOID BURDEN AND DEPRESSIVE SYMPTOMS

\section{Figure Captions}

Figure 1. Box plots indicating the median and interquartile range for total GDS-S scores at each time point for Low $\mathrm{A} \beta$ (dark grey bars) and High $\mathrm{A} \beta$ groups (light grey bars).

Figure 2. Proportion of individuals with clinically significant depressive symptoms (GDS-S

$>5$ ) at each assessment point for the Low $\mathrm{A} \beta$ (dark grey bars) and High $\mathrm{A} \beta$ groups (light grey bars).

** Indicates statistical significance, $p<0.05$

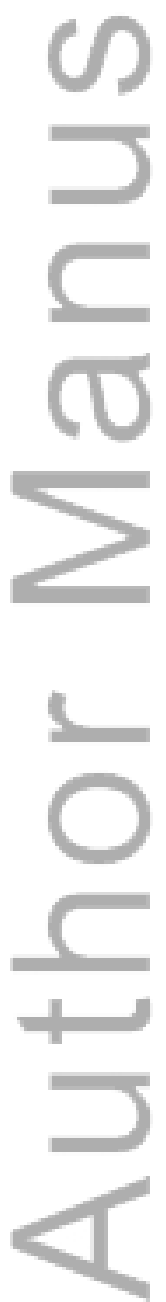

This article is protected by copyright. All rights reserved. 


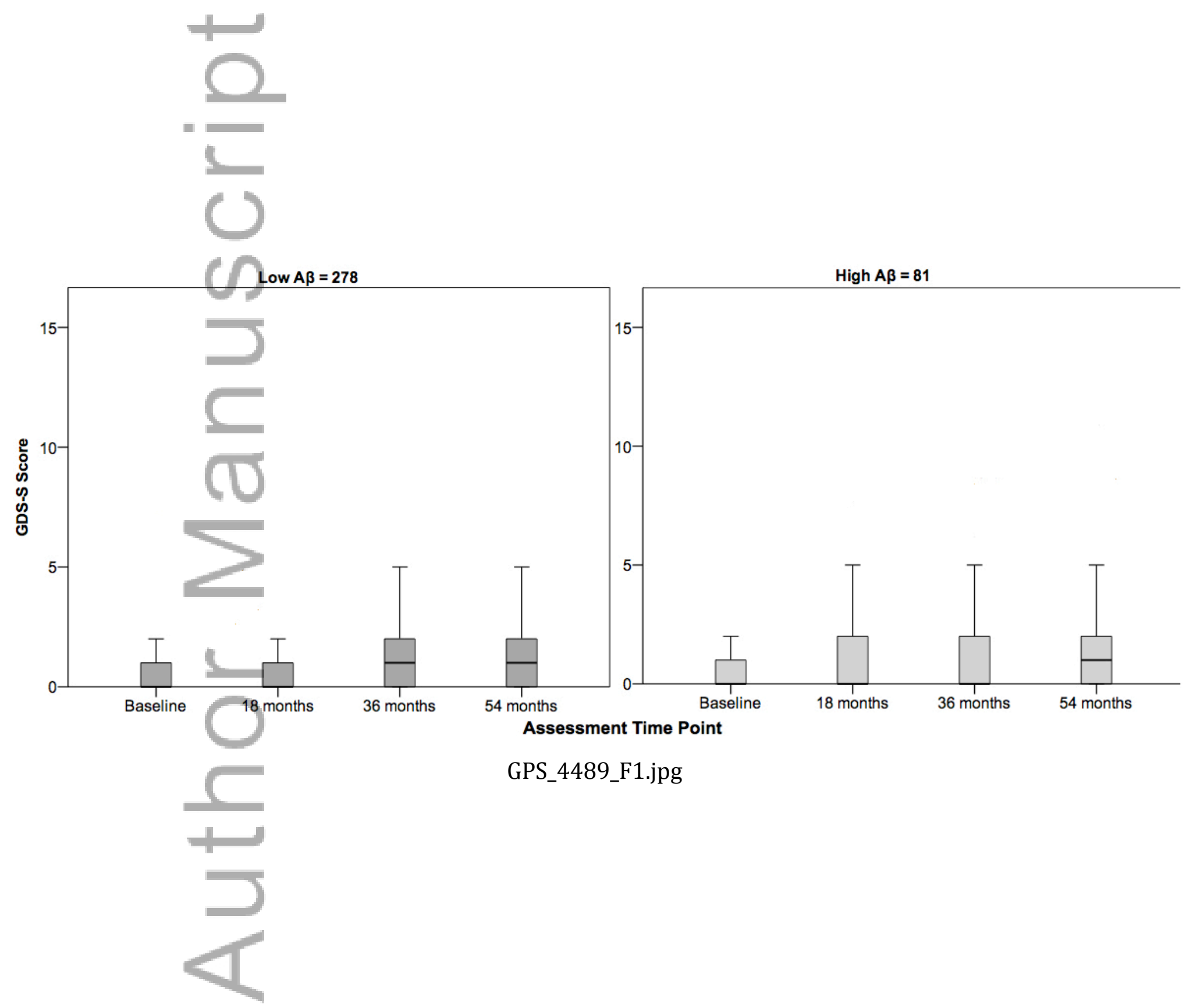

This article is protected by copyright. All rights reserved. 


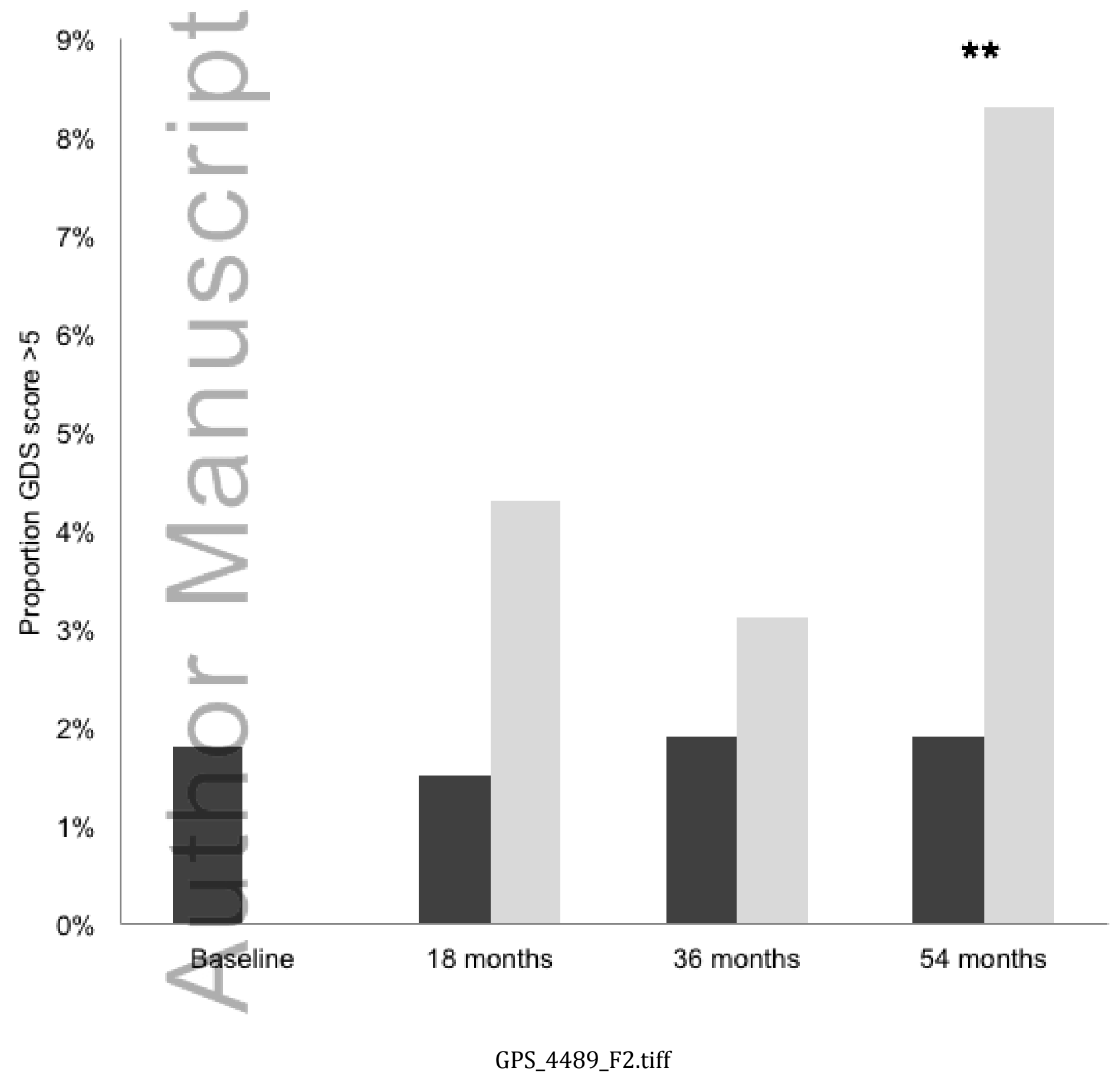

This article is protected by copyright. All rights reserved. 


\section{University Library}

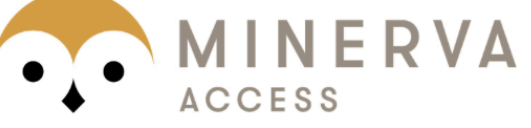

A gateway to Melbourne's research publications

Minerva Access is the Institutional Repository of The University of Melbourne

Author/s:

Harrington, KD;Gould, E;Lim, YY;Ames, D;Pietrzak, RH;Rembach, A;Rainey-Smith, S;Martins, RN;Salvado, O;Villemagne, VL;Rowe, CC;Masters, CL;Maruff, P

Title:

Amyloid burden and incident depressive symptoms in cognitively normal older adults

Date:

2017-04-01

\section{Citation:}

Harrington, K. D., Gould, E., Lim, Y. Y., Ames, D., Pietrzak, R. H., Rembach, A., RaineySmith, S., Martins, R. N., Salvado, O., Villemagne, V. L., Rowe, C. C., Masters, C. L. \& Maruff, P. (2017). Amyloid burden and incident depressive symptoms in cognitively normal older adults. INTERNATIONAL JOURNAL OF GERIATRIC PSYCHIATRY, 32 (4), pp.455-463. https://doi.org/10.1002/gps.4489.

Persistent Link:

http://hdl.handle.net/11343/291208 